\section{SPONTANEOUS CLOSURE OF A MEMBRANOUS VENTRICULAR SEPTAL DEFECT}

\section{NECROPSY FINDING WITH CLINICAL APPLICATION}

\section{BY}

H. J. ALBERS, M.D.

Assistant Resident, Department of Pathology

\author{
S. E. CARROLL, B.A., M.D., F.R.C.S.(C.) \\ Consultant Surgeon
}

AND

\author{
J. C. COLES, B.A., B.Sc., M.D., F.R.C.S.(C.) \\ Assistant Professor of Surgery, University of Western \\ Ontario: Chief of Subdepartment of \\ Cardiovascular Surgery
}

From the Departments of Pathology and of Surgery, Department of Veterans Affairs, Westminster Hospital, London, Ontario, Canada

\section{[With Special Plate]}

Complete anatomical closure of a high ventricular septal defect by the medial tricuspid leaflet as an accidental finding at necropsy was reported for the first time in 1952 by Hartmann from the Pathological Anatomical Institute in Vienna (Professor H. Chiari). In 1960 Majka and associates reported a case of "spontaneous repair of a ventricular septal defect" which came to necropsy at our hospital. Recently a virtually identical case was discovered accidentally at necropsy on an 86-year-old man. This unusual finding is presented together with its surgical application.

\section{Case Discovered at Necropsy}

The patient had been at Westminster Hospital for Domiciliary Care from June, 1956. until his death in December, 1961. His previous history was rather vague, but it appeared that he had suffered from frequent upper respiratory-tract infections and pneumonia. On admission and several times during his stay in hospital he was in early heart failure precipitated by respiratory-tract infections. Treatment of the latter and diuretics were sufficient to overcome this problem. Digitalis was not given until April, 1960, when he was aged 84

Physical examination on admission revealed an emphysematous chest, moist rales at both lung bases, and some oedema of the ankles. The neck veins were not distended and the liver was not palpable. Frequent examinations during the five and a half years preceding his death showed blood-pressure readings around $120 / 70 \mathrm{~mm}$. $\mathrm{Hg}$, an absence of murmurs, and no clinical evidence of cardiac enlargement. Only once a diastolic murmur at the apex radiating to the left axilla. a raised blood-pressure of $160 / 80 \mathrm{~mm}$. $\mathrm{Hg}$, and enlargement of the heart to the left anterior axillary line were reported by an inexperienced physician during routine examination. Shortly before his death the patient became very dyspnoieic. His temperature rose to $103.4^{\circ} \mathrm{F} .\left(39.7^{\circ} \mathrm{C}\right.$.), and he died on December 14, 1961, at the age of 86 years, showing clinical evidence of pneumonia.

At necropsy the lungs showed numerous adhesions as well as macroscopical and microscopical evidence of widespread acute bilateral bronchopneumonia. The heart had a rather globular shape, and a small adhesion was found between the left ventricle and the pericardium. The coronary arteries had numerous calcified atheromatous plaques with nearly complete occlusion of the right coronary artery and the descending branch of the left coronary artery. Collateral vessels were, however, quite numerous, especially along the descending branch. No myocardial infarct was found. The heart weighed $330 \mathrm{~g}$.; the wall of the left ventricle was $1.5 \mathrm{~cm}$. and that of the right ventricle $0.5 \mathrm{~cm}$. in thickness. The ventricles and atria were of normal size. The valve circumferences were : aortic $8.5 \mathrm{~cm}$., mitral $9 \mathrm{~cm}$., tricuspid $12.2 \mathrm{~cm}$., and pulmonary $7.6 \mathrm{~cm}$. A few hard nodules were palpable in the cusps of the aortic valve, which did not alter the structure of this valve to any great extent. The pulmonary and mitral valves showed no abnormality; an interesting abnormality was, however, discovered in the membranous portion of the ventricular septum.

Immediately below and between the right anterior and right posterior leaflets of the aortic valve an oval deficiency measuring 1.5 by $1 \mathrm{~cm}$. was found (Special Plate, Fig. 1). A fibrous ridge 3 to $4 \mathrm{~mm}$. in width separated its posterior upper edge from the insertion of the right posterior (noncoronary) leaflet; anteriorly it bordered directly on the insertion of the right anterior leaflet. It was sealed off completely by the medial leaflet of the tricuspid valve forming an "aneurysmal pouch" that bulged into the right ventricle immediately below the annulus fibrosus of the aortic valve, this pouch being $0.9 \mathrm{~cm}$. at its greatest depth (Special Plate, Fig. 2). When viewed from the left ventricular side the upper surface of the pouch was smooth, whereas the lower half, especially the part adjoining the anterior leaflet of the aortic valve, was irregular. Fibrous ridges, that appeared to arise from the lower margin of the pouch, attenuated into fine fibrous cords inserted into the centre of the pouch. These fibrous structures looked very much like shortened and grossly disfigured chordae tendineae (Special Plate, Fig. 3). Inspection from the right ventricular side showed the bulging " aneurysm" in place of the medial leaflet of the tricuspid valve flanked by perfectly normal posterior and anterior leaflets. The surface of the pouch was smooth (Special Plate, Fig. 4) and blended laterally into the atrial sides of the neighbouring leaflets. The upper half of this "aneurysmal wall" was translucent. No chordae tendineae were present at its lower margin. Microscopical examination of the "pouch" showed the usual histological components of valve leaflets. A few blood-vessels were seen in the lower portion where it bordered on the muscular part of the ventricular septum. Muscular tissue was not found.

No significant gross or microscopical lesions were found elsewhere in the body. There was no evidence of chronic passive congestion of the liver or other manifestations of cardiac disease.

\section{Clinical Application}

One of us (J.C.) employed the septal cusp of the tricuspid valve to close a high membranous ventricular septal defect $(2 \mathrm{~cm}$. in diameter) in January, 1960.

A 27-year-old white male presented with shortness of breath on exertion (8 to 10 steps) and occasional nocturnal dyspnoea. Clinical examination revealed a hyperdynamic heart. There was a Grade III left ventricular tap $2 \mathrm{~cm}$. to the left of the nipple line in the sixth interspace; a right ventricular heave (Grade II) was also present. The pulmonary second sound was loud (Grade III/IV) and split. A Grade IV/V systolic murmur and thrill were present over the entire praecordium. $X$-ray examination revealed left ventricular enlargement and pulmonary plethora. Ventricular strain and hypertrophy were shown on electrocardiography. Right heart catheterization in January, 1960, demonstrated pulmonary bypertension, with a mean pressure of $90 \mathrm{~mm}$. $\mathrm{Hg}$. a right ventricular pressure of $100 \mathrm{~mm}$. $\mathrm{Hg}$. and evidence of a large left-to-right shunt at the ventricular level. The pulmonary flow was estimated at 35 litres per minute, the systemic flow at 5 litres per minute.

Operation was felt to be indicated and was carried out on January 20, 1960, through a midline sternum-splitting incision. The patient was placed on cardio-pulmonary 


\section{H. J. ALBERS ET $A L .:$ SPONTANEOUS CLOSURE OF VENTRICULAR SEPTAL DEFECT}

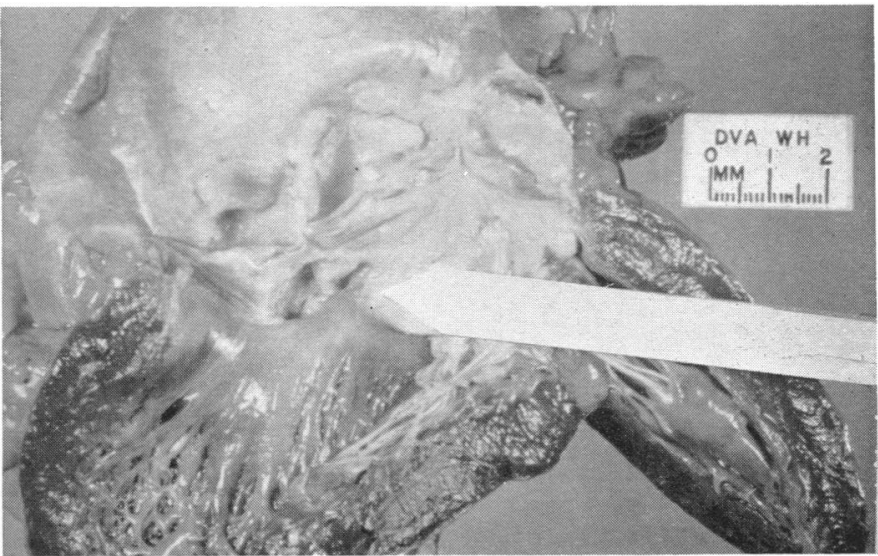

FIG. 1.-Left ventricle and ascending aorta with arrow pointing to defect in membranous part of ventricular septum.

FIg. 2.-Vertical section through defect (with explanatory diagram).

Fig. 3.-Close-up view of defect flanked by right anterior and right posterior (non-coronary) leattets of aortic valve. Note fibrous cords (? chordae tendineae) in centre of pouch.

FIg 4.-Close-up view of tricuspid valve with arrow pointing to medial leaflet sealing defect.

Fig. 1
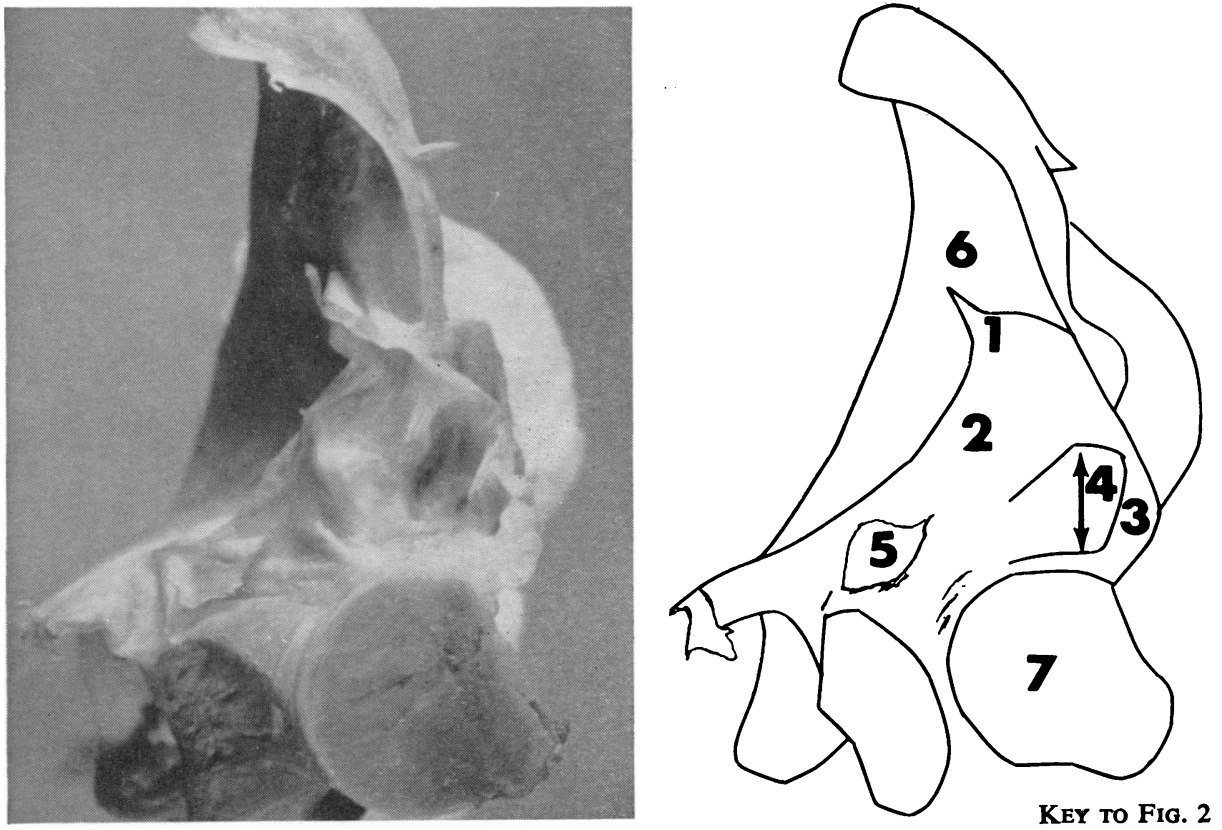

1. Right posterior aortic cusp

2. Right anterior aortic cusp

3. Medial tricuspid cusp

4. Ventricular septal defect

5. Left aortic cusp

6. Aorta

7. Ventricular septal muscle

Fig. 2

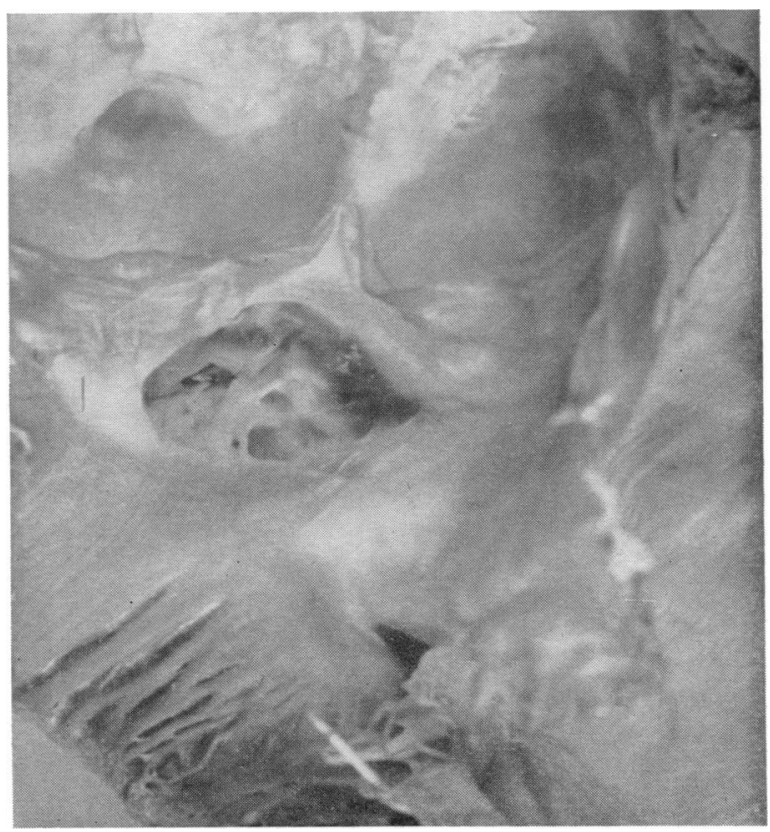

FIG. 3

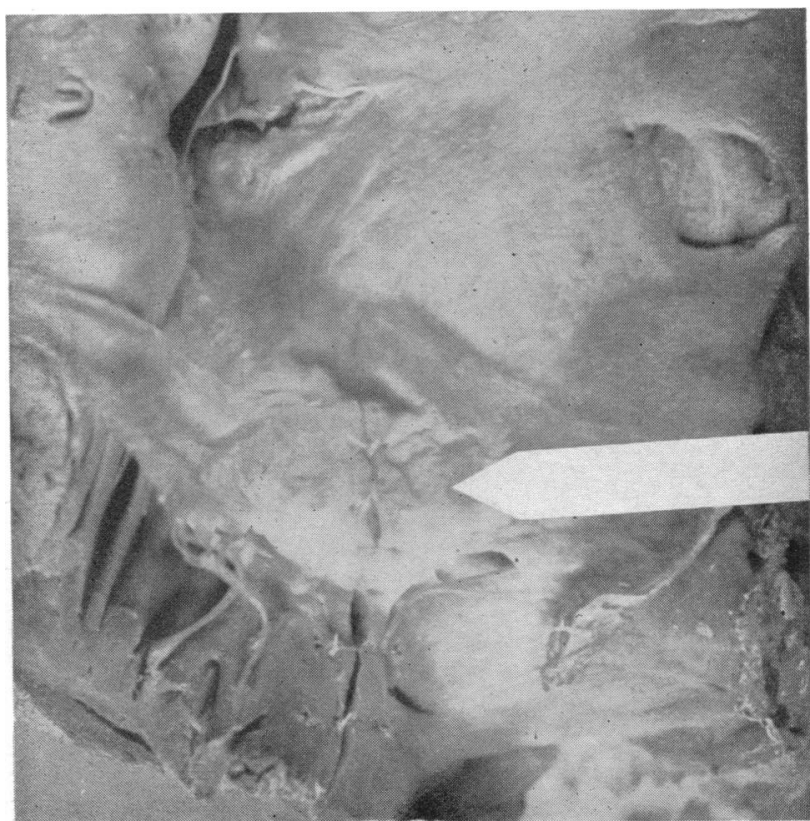

Fio. 4 
bypass with a disk oxygenator and De Bakey rotary pumps. A flow rate of 2.2 litres per square metre of body surface was maintained throughout. A heat-exchanger was incorporated in the arterial line to maintain an oesophageal temperature of $32^{\circ} \mathrm{C}$.

At the time of right ventriculotomy the septal cusp of the tricuspid valve was found to be relatively immobile and held in close proximity to the defect by several short chordae tendineae. It was obvious that the septal cusp was acting as a buttress only, since the excursion during systole and diastole was almost nil. The septal leaflet of the tricuspid valve was detached from its chordae tendineae and sutured to the margin of the defect by 11 interrupted 4-0 silk sutures. Cardio-pulmonary bypass was discontinued and satisfactory cardiac action persisted. Pressures (in $\mathrm{mm} . \mathrm{Hg}$ ) at this stage were: right ventricle $30 / 0$, pulmonary artery $30 / 18$, left ventricle $120 / 0$, and aorta $120 / 85$. Oxygen saturation as determined on the Kipp oximeter was as follows: superior vena cava $72 \%$, right atrium $74 \%$, right ventricle $70 \%$, pulmonary artery $72 \%$. A finger inserted into the right atrium at this time revealed a faint systolic thrill over the most medial portion of the tricuspid valve.

The post-operative course was uneventful until the twelfth day, when a wound abscess occurred. This was drained, and the patient left hospital ten days later in good condition. Subsequent catheterization (July 20, 1960) demonstrated no increase in oxygen saturation from the superior vena cava, the right atrium, the right ventricle, or the pulmonary artery. The pressure in the right ventricle remained at $30 / 0 \mathrm{~mm} . \mathrm{Hg}$ and that in the pulmonary artery at $30 / 12 \mathrm{~mm}$. $\mathrm{Hg}$. A faint short (Grade I/IV) systolic murmur was heard over the parasternal area. The patient remains (May, 1962) asymptomatic.

\section{Discussion}

Though murmurs have been known to decrease or disappear in children with ventricular septal defect, and though physiological studies have demonstrated decreased shunts in proved cases, spontaneous anatomical closure of a membranous ventricular septal defect has been reported only twice before the present case. Hartmann (1952) described a defect similar to this one in a man of 67 years, with death from pulmonary embolism. Majka et al. (1960) observed another case in our hospital, with death due to rupture of a dissecting aneurysm.

The various types of ventricular septal defect have been well described (Gould, 1960 ; and others). Muscular defects are more likely to close spontaneously. The variations in the septal cusp of the tricuspid valve, particularly concerning the length of its chordae tendineae, are perhaps not so widely known.

The clinical records of our necropsy case, going back to the Boer War, give no record of a systolic murmur. The heart was not enlarged and the right ventricle and atrium were normal in thickness. There was no definite evidence of inflammatory reaction in the fused cusp and no evidence of rheumatic heart disease. The man died from pneumonia without any signs of heart disease at 86 years of age. In the absence of contradictory evidence it is postulated that the defect closed during the time when the right ventricular pressure exceeded that of the left ventricle-that is, before or shortly after birth. It is a matter of clinical interest that there was no clinical or pathological evidence of tricuspid regurgitation.

Certain anatomical variants of the tricuspid valve make it possible to fix the septal cusp to the ventricular septum without producing gross tricuspid insufficiency. Necropsy and clinical evidence is presented to support this.
It is axiomatic that prosthetic material should not be inserted into patients unnecessarily. The authors submit that a ventricular septal defect may be closed with the septal leaflet of the tricuspid valve in suitable cases.

\section{Summary}

An incidental finding at post-mortem examination in an 86-year-old veteran was a defect in the membranous portion of the ventricular septum which had been closed spontaneously by fusion of the septal leaf of the tricuspid valve to margins of the defect. It is postulated that the closure occurred before birth.

A surgical case is also presented in which the septal cusp of the tricuspid valve was used to close a membranous ventricular septal defect without production of tricuspid regurgitation.

In selected cases ventricular septal defects may be repaired with the septal leaflet of the tricuspid valve in preference to the use of prosthetic material.

We wish to express our gratitude to Dr. J. C. Paterson for generous advice and to Dr. J. A. Lewis for permission to publish the necropsy case.

\section{ADDENDUM}

A further case of spontaneous closure of a membranous (high) septal defect has been found as an incidental finding at a necropsy performed by Dr. Ross Malone, of St. Joseph's Hospital, London, Ontario. This brings to three the number of cases found post mortem at this centre.

\section{BIBLIOGRAPHY}

Azevedo, A. de C., Toledo, A. N., de Carvalho, A. A., Zaniolo, W., Dohmann, H., and Roubach, R. (1958). Acta cardiol. (Brux.), 13, 513

Cleland, W. P. (1960). In Modern Trends in Cardiac Surgery, ed. H. R. S. Harley, pp. 108-21. Butterworth, Toronto.

Downing, D. F. (1959). Amer. Heart J., 57, 669.

Du Shane, J. W., and Kirklin, J. W. (1960). Circulation, 21, 13. Evans, J. R., Rowe, R. D., and Keith, J. D. (1960). Ibid., 22, 1044.

Gould, S. E. (1960). Pathology of the Heart, 2nd ed. Blackwell, Oxford.

Hartmann, G. (1952). Zbl. allg. Path. path. Anat., 88, 241

Hoffman, J. I., Rudolph, A. M., Nadas, A. S., and Gross, R. E. (1960). Circulation, 22, 405.

Kirklin, J. W., McGoon, D. C., and Du Shane, J. W. (1960). J. thorac, cardiovasc, Surg, 40, 763.

Majka, M., Ryan, J., and Bondy, D. C. (1960). Canad. med. Ass. J., 82, 317 .

Nadas, A. S., Scott, L. P., Hauck, A. J., and Rudolph, A. M. (1961). New Engl. J. Med., 264, 309.

Eleven scholarships have been awarded to nurses and midwives of the British Commonwealth during 1962 by the British Commonwealth Nurses War Memorial Fund. The countries receiving scholarships are United Kingdom (6), Canada (1), India (1), Rhodesia and Nyasaland (1), Hong Kong (2); and scholars will be going from these countries to study in U.S.A., Canada, New Zealand, Scandinavia, Holland, Finland, and the United Kingdom. These scholarships are for postgraduate study in a country other than the scholar's own, and are valued at $£ 350$ each. The British Commonwealth Nurses War Memorial Fund was founded in 1946 to provide a memorial to nurses and midwives who gave their lives in the second world war, and the first part of the memorial is a chapel in Westminster Abbey. Queen Elizabeth the Queen Mother is patron and the Princess Royal is the vice-patron of the fund. Since the scholarships were first allocated in 1950 , over $£ 40,000$ has been spent in this way, and more than 200 scholars have gone out under the auspices of the fund. 